\title{
Sustainable coastal development indicator system studies in Latvia
}

\author{
R. Ernšteins, J. Kauliņš \& I. Kudreņickis \\ Institute for Environmental Science and Management, \\ University of Latvia, Riga, Latvia
}

\begin{abstract}
An appropriate characterization of preconditions and trends for decision-making towards the sustainable development of coastal territories in Latvia determines the need for further studies of existing wide experience and particular methods for development of European, nationwide and/or local coastal information systems. Analysis of the framework and content establishment as well as data gathering and calculation approaches for sustainable coastal development (SCD) indicators system creation, functioning and future challenges has been carried out based on a specific set of coastal indicators elaborated at the EU level, application experience of the related EU Interreg IIIC Deduce project and, particularly, the indicators system test run in Latvia, whilst also including the following practice evaluation by coastal municipalities and other main actors in the field.

An initial SCD indicator system proposal for Latvia is elaborated, recognizing the main typical features of nature-environmental and socio-economic conditions, spatial scale and data gathering selective differences as well as identifying institutions and actors to be involved. The system proposal distinguishes 24 indicators, including ones for the assessment of the development of human resources and integrated management capacities, with this constituting the additional and most important SCD sector goal. These several integrative indicators shall provide information on integrated coastal sustainability and its management, particularly with regard to the efficiency of the coastal communication process. However, further testing and elaborations are required to secure the evaluation of coastal awareness, public participation, municipal planning and practice, as well as to integrate this together with well-tested bottom-up or participatory designed indicators system application.
\end{abstract}

Keywords: integrated coastal zone management (ICZM), sustainability information resources, sustainable coastal development indicators systems. 


\section{Introduction}

The availability of appropriate sustainable development information resources are the primary necessity for the wide understanding of diverse development processes in complex coastal territories and, if adequately elaborated, could be used as effective instruments for both the assessment and planning-management of coastal area sustainability. To develop an adequate information system and, further on, related indicators systems, having met all possible sectorial and, in particular, interdisciplinary demands, is certainly more difficult for coastal systems as opposed to integrated nature-environmental and social-economic systems - there are obviously serious differences between the list of simple environmental indicators and the system of sustainable development indicators.

The indicator systems (actually, mostly of the lists of indicators chosen) are applied stepwise in municipalities in Latvia and during the last decade have been applied in coastal territories. The most adequate systems for local decision making, considering the very important subjects of public awareness and behaviour, are those being developed based on the active and wide involvement of all local target groups - these are known as participatory indicators' systems [1]. Evaluating this experience of ongoing tests in Latvia to develop the comprehensive environmental and/or sustainability indicators system, one should recognize again the principal necessity of complementary integration and also, further on, the integrated communication of both by the "top-down" approach and the "bottom-up" approach designed and implemented indicator systems or, at least, to manage some complementary elements of both systems [2].

For applicability analysis of the national level "top-down" type indicators system, the set of SCD indicators taken is that developed in Europe by the EU ICZM expert group (in particular, the working sub-group on indicators and data - WG ID) in 2003 and being elaborated for practice calculations and test runs for six EU coastal countries (including Latvia) during application [3] of the EU Interreg IIIC project Deduce (2005-2007). The structure of the Deduce indicators system is based on measuring the indicators' values within seven recognized principal SCD goal sectors [6]: (i) controlling as appropriate further development of the undeveloped coast; (ii) protecting, enhancing and celebrating natural and cultural diversity; (iii) promoting and supporting a dynamic and sustainable coastal economy; (iv) ensuring that beaches are clean and that coastal waters are unpolluted; (v) reducing social exclusion and promoting social cohesion in coastal communities; (vi) using natural resources wisely; (vii) recognizing the threat to coastal zones posed by climate change and ensuring appropriate and ecologically responsible coastal protection. The indicators set includes 27 indicators and 45 related measurements.

Besides the project-based test run in Latvia, there are some important questions to be studied and discussed on the following challenges for "topdown" indicator systems when tackling local coastal sustainability issues:

- does the proposed indicator system cover all principal aspects of the sustainable development of coastal territories; 
- how can the local features be adequately incorporated; are the local and regional communities and local target groups interested and subsequently can they be involved in the realization of such indicators;

- $\quad$ how could these indicators be used for local development work.

Elaborating upon national/regional and local coastal case study research prepares a further practical background and also gives theoretical frames for indicator system development and the renewal of ICZM strategies.

\section{SCD indicators calculation: Deduce project case in Latvia}

According to the data available in Latvia, it is important not only to calculate the necessary number of indicator measurements, but also to evaluate whether the whole proposed list of indicators [3] will give the relevant information regarding all requirements for sustainable development planning in coastal territories. Initially, we shall discuss both calculation results as well as principal content relevance of different groups of indicators through the test run experience in Latvia and then later we will analyze both administrative and technical problems regarding coastal data gathering and processing, as all necessary activities have to be properly prepared and realized in practice to provide only relevant information for decision making.

\subsection{EU indicator system development: evaluations}

The Deduce project recommendations for the EU [4] included the main results and conclusions, evaluating the calculation process itself, reviewing the set of SCD indicators provided by the EU WG-ID, as well as further work needed to build a complete sustainability evaluation model. The current SCD indicators framework tested could be of certain use in the decisions systems in European coastal zones, but further developments of the proposed indicator system are to be elaborated. During the Deduce project several measurements were recognized by partners as being relevant for coastal sustainability assessment, but not included in the set of indicators proposed by the WG ID in 2003. These are: the use of marine space; the sustainability of maritime activities; adapting biodiversity indicators; the state and evolution of coastal water masses; social conditions; further adaptations to fisheries indicators; and other potential effects of climate change [4].

During the Deduce project work in Latvia, including a national assessment workshop, the following principal areas of missing indicators were detected: coastal landscape characterizing indicators - although development of measurement methodology for this purpose may be quite sophisticated, this indicator is also very important; polluted coastal sites indicators - mapping of the distribution of polluted sites in the coastal zone; coastal communication indicators - the whole complete set of elements for integrative communication (coastal information and education, coastal participation and environment friendly activities). Another useful discussion could be on the development of a particular measurement revealing (i) the threats to biodiversity, (ii) the 
risks/threats to the sustainability of maritime activities and (iii) the lifestyle of the coastal population, which will be discussed next.

At the moment, different indicators characterizing threats included in the Deduce indicators system are divided into different objectives. For the practical application of planning purposes it is important to clearly show both the origins and priority ranking of the threats to biodiversity. These threats may be made not only by the land-transformation, but also by the industrial development of coastal cities and related risks of this type. One measurement example may be the level of fragmentation of natural habitats; there could be on the whole be a sufficient amount of natural territories, but biodiversity conservation in the overall coastal area may suffer from the fragmentation of these territories.

The sustainability of maritime activities (and indirectly - activities in the coastal zone) also has to be evaluated in relation to the threats disrupting these activities. It is important to develop a systematic and broad definition and to identify threats/risks of different types for this purpose. At the moment the Deduce indicators measure the amount of oil spills, but there may be more risks/threats that need to be taken into account. The current status and developmental tendencies of coastal fisheries is particularly important due to its status in terms of tradition, its role in cultural heritage and the coastal economy. Thus, the particular measurements more deeply revealing the sustainability of coastal fishery processes would be more apparent with measurements such as trends in changes in the number of fishermen and the evaluation of the ratio between the economic value of landings of the fish stocks, which are within safe biological limits, against those fish stocks that are over fished etc.

When defining the scope of social conditions, it is worth measuring how the current lifestyle of the coastal population is related to coastal and marine resources, thus here additional measurements may be useful: the level at which the coastal population identify themselves as coastal inhabitants, having particular features of life style and special interest characteristics of coastal and marine areas; the level (percentage) of the coastal population for which employment is directly related to coastal and marine resources - even though employment patterns are measured under other objectives, this measurement has not only meaning for the economy but is also a very important indicator of social conditions.

The indicator calculation process itself in Latvia has also had a number of difficulties, e.g., there were no national level data at all for several measurements for indicators. There are important indicators that could not be recognized at the local municipality level, adding to the lack of coastal indicator information as well as the fact that at the moment there are no statistics for several topics, which all together are creating a number of coastal sustainability measurement problems. Different institutions are submitting their statistical reports to different state management institutions, necessitating the establishment of a kind of national focal point (coastal observatory), collecting and eventually integrating all relevant coastal information and even coastal communication. This may serve needs not only limited to the development of the process of coastal data preparation. Of course, these specific comments as well as those more general 
ones above may be elaborated upon in more detail, but all this has to be taken into account when planning both a national SCD indicator system and for joint EU SCD policy applications, as there might be perceived some kind of similarities for Eastern Europe.

There are also several cross-national generalizations and practical recommendations found after the test run in Latvia, which might be useful for other organizations and countries interested in the use of existing or a new design of sustainable coastal development indicators. There are certain indicators in the Deduce set actually expressing significant differences, understandably, between the Latvian coast of the Baltic Sea and, for example, the Mediterranean coast. Thus selective approaches or variable measurements for the same indicator could be introduced parallel to and in some cases, maybe even the development of, more appropriate indicators, which can really serve as a catalyst for decisionmaking. Another example is the decision on the selection of the best indicators to characterize social exclusion in order to get the following: (i) the right social exclusion indicators, (ii) a system of measurement to provide reliable data, and (iii) a method for interpretation. The next type of problem is the proposed methodology to calculate, for example, threats to the coastal zone that require rather sophisticated measurements; however, taking into account Latvia's conditions these data may also be obtained by simpler methodologies. Furthermore, the division between coastal, urban, and rural territories has to be carried out as in the opposite case, applying only the integrative indicator, the urban population changes in coastal cities are dominating those eventually important changes in rural areas. Finally, the statistical system has to be introduced in such a way as to allow us to evaluate the change of population within different distances from the coast. This task is particularly challenging currently for Latvia in the context of ongoing administrative territorial reform in order to create larger municipal units.

\subsection{SCD in Latvia: general assessments}

As for the preparation of short overview conclusions for SCD in Latvia carried out after indicator test calculations within the EU Deduce project, we shall first recall two major factor groups to be recognized in the entire indicator system in general. One of them directly describes human activity and is comparatively well measurable, while the other one reflects different processes in the natural environment and the impact of human activities here is recordable only indirectly, if at all. These overview descriptions of both factor groups will emphasize only topical feature issues.

Demographical and economic development tendencies in the coastal areas of Latvia differ considerably only in some parameters when compared to those tendencies in inland territories. Mostly they are reflected as an increase of the load on coastal land, both in terms of growth intensity and also the involvement of new territories into economic processes. However, the main determining spatial factor for this load growth is not only the attraction of the coast itself, but also the presence and rapid developments of big cities (primarily, the capital city of Riga) located in the coastal zone. 
However, economic capital and social capital, particularly in rural coastal territories, are not treated sufficiently due to the methodological specifications. In the economic sector we can identify the underdeveloped tourism sector in the economy of the coastal areas (outside major coastal cities). Significant growth in the tourism sector may be identified for coastal cities, whilst growth in other coastal territories has been much slower; however, it was more rapid compared to inland rural territories Taking into account that the resort economy might be the main branch of the coastal rural economy in Latvia, its insufficient level of development, and even planning, leads to a weak coastal economy in general.

As for social capital, the unemployment level in coastal territories is lower than in inland, and tends to decrease in all territories. However, once again, this tendency is mostly affected by Riga; in remote areas this situation is not that favourable. In fact, the Deduce calculations did not provide sufficient data on unemployment, particularly in rural coastal territories. An interesting conclusion, particularly for the case of Latvia, is that the impact of the coast on social exclusion is quite inconsiderable.

Particular sorts of pollution either do not show signs of change or even have a tendency to slightly decrease. Activities having an impact on biodiversity are not critical, according to the indicators applied, except for one - the over fishing of cod in the Baltic Sea. Unfortunately, the assessment of natural factors is not fully unequivocal due to the lack of satisfactory data. An exception is for erosion processes, which of late have intensified, particularly in coastal territories.

The coastal sustainability of Latvia in terms of nature capital currently may be identified as good. The main factors for such a conclusion are based on the following. Firstly, the coastal zone in Latvia contains many valuable areas with unique species, biodiversity, biotopes and undamaged nature. Secondly, the amount of protected areas increased between 2000 and 2005, and at present about one third of the coastal area (land $10 \mathrm{~km}$ buffer) is under EU legislative protection. Climatic conditions are not favourable for the development of intensive agriculture in coastal areas and territories of arable land are not likely to increase. Thirdly, there is a high concentration and even a slight increase in semi-natural habitats in the coastal areas of Latvia (slightly higher than in the inland territories).

This present positive situation is rather hard to evaluate as fully stable; it should be assessed as good for today, but with rather a high risk of vulnerability. The Deduce project indicator evaluations allow us to identify main sectors that might be negatively affected and they are: coastal land biodiversity; sea area biodiversity; the availability of recreational territories; rights of public access to coastal territory. The following factors are the main threats to coastal sustainability. Firstly, the concentration of businesses in cities and towns increases the demand for development in urban coastal territories. Secondly, the shortage of suitable rural lands for building may be noticeable in the coastal zone in the coming 5-10 years, this, in turn, will cause a risk for the transformation of previous agricultural land (which, according to the traditional low-intensity farming, can be assessed as semi-natural land) and woodland into built-up land. Thirdly is the general trend of growing cargo traffic flow on the roads near the 
coast, determined by the impact of large cities (Riga and Liepaja) and also the dramatic increase in the number of privately owned cars as a coefficient factor. Fourth, port traffic loading in the Gulf of Riga has been increasing. From the point of view of sea biodiversity it is a risk, as the Gulf of Riga is a vulnerable sea territory, which, according to future plans, will be crossed by intensive cargo ship traffic.

In general, from the current SCD indicators application, it can be concluded that the development of coastal territories in Latvia has a comparatively wellbalanced character and environmental protection counter-pressure is comparatively adequate and helps to set limits on the negative impacts caused by the extensive coastal developments. However, existing and eventual conflict situations, undiscovered by these particular SCD indicators, should additionally be taken into account, e.g., several "hot spots" where protected biotopes are endangered by development activities.

Lack of representation of some conflicting processes in the SCD indicators application results shows both the unsystematic character of some particular related indicator calculations and certain drawbacks of the whole indicator system. Some important SCD indicator system evaluation questions also remain unanswered, e.g., the necessary developments for integrative assessments; coastal system sustainability judgements; the implications for and realization of integrated decision-making.

There are two threats to the coastal sustainability assessment when applying top-down statistical system possibilities in Latvia in the future. Firstly, it would not be possible to correctly distinguish and compare coastal administrative territories since they will be not uniform and heterogeneous due to the ongoing bottom-up interests-based administratively-territorial reform. Secondly, the policy of state statistical institutions are directed towards reflection of statistical information only according to the statistical regions, which may eradicate local statistics and the monitoring possibilities of several important demographic and socioeconomic parameters of the municipalities. Obviously, raising practical interest and involvement of local coastal municipalities will be a must for the next stage of SCD indicator system development in Latvia, combining the topdown approach with jointly agreed and bottom-up based SCD measurement methodology.

\section{Indicator system development for Latvia}

Coastal participatory communication and partnerships shall be seen as a new and unsystematically developed challenge and, practically, an aim for the necessarily integrated coastal management re-enhancement. Certain sets of preconditions are to be recognized [5], while elaborating the frame for environmental information management and, particularly, system development in coastal municipalities within the sustainable development context. Firstly, the environmental information should be considered as a part of the whole sustainability communication cycle process, taking into account mutual interaction with all other communication components, such as environmental-sustainability 
education and training, as well as related participation and partnerships building, and environmentally friendly behaviour [6]. Further on, an information cooperation system will be established, where municipalities should incorporate all principal actors, e.g., general public interest groups and private business, selfgovernance and governmental institutions as well as mediator actors - media and non-governmental organizations, science and education. Parallel to this, the information system should reflect and integrate various environmental management dimensions on the coast, e.g., national (public) and municipal, corporate and household as well as regional/international environmental and sustainability management dimensions. This information system should include all disciplinary and integrative sustainability information resources, which should be identified and analyzed together with corresponding coastal communication tools to be systematically introduced and systemically used.

The SCD indicator system proposal elaborated for measuring coastal sustainability in Latvia is based on that developed in the Deduce project study [3] and also possible incorporations as mentioned above. Main characteristic features typical for geographical and socio-economic conditions in Latvia, spatial scale differences in sustainability evaluation measurements and, in some cases, data availability in Latvia, are taken into account. There are also defined institutions, responsible for the maintenance of and public access to data sets.

\subsection{System structure and content proposal}

The SCD indicators system proposal distinguishes eight SCD sector goals and the development of each sector is to be measured by a chosen set of 24 indicators (in total by 34 measurements). Compared to the previously discussed indicator system, the first seven sector goals could be kept adequate to those of Deduce [3], but taking into account the project test run evaluation proposals, there is the obvious need for the introduction of additional goal number eight, the most important one - to develop human resources and integrated management capacity. This version is developed in order to comprise several integrative indicators, which shall provide information on coastal management, particularly on the efficiency of the coastal communication process. This group of indicators shall be further tested and elaborated upon to reflect the following: coastal awareness among the population; the state of the environment and evaluation of change tendencies; the state of local economy and evaluation of development trends; the evaluation of work of municipalities; and the evaluation of planning practice. The short summary of the structure of the indicator system is provided in Table 1.

Since information necessary for this additional group of indicators is neither assessable from the state centralized statistics, nor from activities of particular institutions, it can be acquired only directly from via formal/informal surveys (interviews and questionnaires), which is quite time and resources consuming; however, as these indicators represent the slowly changing processes, the measurements will not be taken so frequently. Sampling frequency is individual for each measurement, taking into account the character of the appropriate process as well as the dynamics of socio-economic processes in Latvia. Many 
Table 1: $\quad$ Indicators system proposal.

\begin{tabular}{|c|c|c|c|c|}
\hline Goal & Indicator & Measurement & $\begin{array}{c}\text { Proposed responsible } \\
\text { institution for measurement }\end{array}$ & \begin{tabular}{|c|} 
Measurement \\
/Sampling \\
frequency \\
(years)
\end{tabular} \\
\hline \multirow{6}{*}{ I } & 1 & $\begin{array}{l}\text { Size and proportion of the population living } \\
\text { in the coastal zone }\end{array}$ & \begin{tabular}{|c|}
$\begin{array}{c}\text { Central Statistic Bureau of } \\
\text { Latvia }\end{array}$ \\
\end{tabular} & 5 \\
\hline & 2 & $\begin{array}{l}\text { Area (percent) of built-up land (by distance } \\
\text { from the coastline) }\end{array}$ & \multirow{2}{*}{$\begin{array}{c}\text { State agency "Latvian } \\
\text { Environment, Geology and } \\
\text { Meteorology Agency" }\end{array}$} & 5 \\
\hline & \multirow{2}{*}{3} & $\begin{array}{l}\text { Rate of development on previously } \\
\text { undeveloped land }\end{array}$ & & 5 \\
\hline & & $\begin{array}{l}\text { New development of previously developed } \\
\text { land }\end{array}$ & Municipalities & 5 \\
\hline & 4 & $\begin{array}{l}\text { Volume of traffic on main coastal } \\
\text { motorways }\end{array}$ & $\begin{array}{l}\text { SJSC "Latvian State } \\
\text { Roads" }\end{array}$ & 5 \\
\hline & 5 & $\begin{array}{l}\text { Proportion of agricultural land farmed } \\
\text { intensively }\end{array}$ & $\begin{array}{c}\text { State agency "Latvian } \\
\text { Environment, Geology and }\end{array}$ & 5 \\
\hline \multirow[b]{2}{*}{ II } & 6 & Area of semi-natural habitats & Meteorology Agency" & 5 \\
\hline & 7 & Area of protected biotopes in coastal zone & $\begin{array}{l}\text { Faculty of Biology of } \\
\text { University of Latvia }\end{array}$ & 5 \\
\hline \multirow{6}{*}{ III } & \multirow[t]{2}{*}{8} & $\begin{array}{l}\text { Full time, part time and seasonal } \\
\text { employment per sector }\end{array}$ & \multirow{2}{*}{$\begin{array}{l}\text { Central Statistic Bureau of } \\
\text { Latvia \& municipalities }\end{array}$} & 1 \\
\hline & & Value added per sector & & 1 \\
\hline & 9 & Total volume of goods handled per port & $\begin{array}{c}\text { Central Statistic Bureau of } \\
\text { Latvia }\end{array}$ & 1 \\
\hline & \multirow[t]{2}{*}{10} & $\begin{array}{l}\text { Number of overnight stays in tourist } \\
\text { accommodation }\end{array}$ & \multirow{3}{*}{$\begin{array}{l}\text { Central Statistic Bureau of } \\
\text { Latvia }\end{array}$} & 1 \\
\hline & & Occupancy rate of bed places & & 1 \\
\hline & 11 & $\begin{array}{l}\text { Ratio of overnight stays par number of } \\
\text { residents }\end{array}$ & & 1 \\
\hline \multirow{5}{*}{ IV } & 12 & $\begin{array}{l}\text { Percent of coastal bathing waters compliant } \\
\text { with the guide value of the European } \\
\text { Bathing Water Directive }\end{array}$ & $\begin{array}{l}\text { State agency "Public } \\
\text { Health Agency" }\end{array}$ & 1 \\
\hline & 13 & $\begin{array}{l}\text { Volume of litter collected per given length } \\
\text { of shoreline }\end{array}$ & $\begin{array}{c}\text { Central Statistic Bureau \& } \\
\text { UL ESAM Department }\end{array}$ & 1 \\
\hline & 14 & $\begin{array}{l}\text { Average winter concentrations of nitrates } \\
\text { and phosphates in coastal waters }\end{array}$ & $\begin{array}{l}\text { Environmental Agency \& } \\
\text { Institute of Hydroecology }\end{array}$ & 1 \\
\hline & \multirow[b]{2}{*}{15} & Volume of accidental oil spills & \multirow{2}{*}{$\begin{array}{l}\text { Marine and Inland Waters } \\
\text { Administration of the State } \\
\text { Environmental Service }\end{array}$} & 1 \\
\hline & & $\begin{array}{l}\text { Number of observed oil slicks from aerial } \\
\text { surveillance }\end{array}$ & & 1 \\
\hline \multirow{5}{*}{ V } & 16 & Indices of social exclusion in coastal zone & Central Statistic Bureau & 1 \\
\hline & \multirow{3}{*}{17} & Average household income & \begin{tabular}{|c|} 
Central Statistic Bureau \& \\
State Revenue Service \\
\end{tabular} & 1 \\
\hline & & $\begin{array}{l}\text { Percent of population with a higher } \\
\text { educational qualification }\end{array}$ & Central Statistic Bureau & 5 \\
\hline & & Value of residential property & State Land Service & 5 \\
\hline & 18 & Ration of first to second homes & $\begin{array}{l}\text { Central Statistic Bureau \& } \\
\text { State Revenue Service }\end{array}$ & 5 \\
\hline
\end{tabular}


Table 1: $\quad$ Continued.

\begin{tabular}{|c|c|c|c|c|}
\hline Goal & Indicator & Measurement & $\begin{array}{c}\text { Proposed responsible } \\
\text { institution for measurement }\end{array}$ & $\begin{array}{c}\text { Measurement } \\
\text { /Sampling } \\
\text { frequency } \\
\text { (years) } \\
\end{array}$ \\
\hline \multirow{3}{*}{ VI } & \multirow{3}{*}{19} & $\begin{array}{l}\text { State of the main fish stocks by species and } \\
\text { sea area }\end{array}$ & \multirow{3}{*}{$\begin{array}{c}\text { State agency "Latvian Fish } \\
\text { Resources Agency" }\end{array}$} & 5 \\
\hline & & Landings by species & & 1 \\
\hline & & Value of landings by port and species & & 1 \\
\hline \multirow{4}{*}{ VII } & \multirow{2}{*}{20} & Length of protected and defended coastline & $\begin{array}{l}\text { Latvian Geospatial } \\
\text { Information Agency" }\end{array}$ & 10 \\
\hline & & Length of dynamic coastline & $\begin{array}{l}\text { Environmental agency \& } \\
\text { UL Faculty of Geography }\end{array}$ & 10 \\
\hline & \multirow{2}{*}{21} & $\begin{array}{l}\text { Number of people living within "at risk" } \\
\text { zone }\end{array}$ & \begin{tabular}{|c|} 
Municipalities \& \\
Environmental agency \& \\
UL Faculty of Geography
\end{tabular} & 10 \\
\hline & & $\begin{array}{l}\text { Value of economic assets within "at risk } \\
\text { zone" }\end{array}$ & $\begin{array}{l}\text { State Land Service \& } \\
\text { Latvian Geospatial } \\
\text { Information Agency }\end{array}$ & 10 \\
\hline \multirow{5}{*}{ VIII } & 22 & $\begin{array}{l}\text { Coastal awareness of population living in } \\
\text { coastal zone }\end{array}$ & \multirow{5}{*}{$\begin{array}{l}\text { Municipalities \& UL } \\
\text { ESAM Department }\end{array}$} & 3-5 \\
\hline & 23 & Assessment of state and tendencies & & $5-10$ \\
\hline & & & & $5-10$ \\
\hline & \multirow{2}{*}{24} & \multirow{2}{*}{ Assessment of coastal management } & & $5-10$ \\
\hline & & & & $5-10$ \\
\hline
\end{tabular}

socio-economic parameters are rather stable and slow changing in the economies with a stable character, thus their observation might occur within a several year interval. In Latvia, on the contrary, parameters might change considerably even within one year and an insufficient observation frequency might create failures in the timely identification and evaluation of tendencies, thereby affecting coastal sustainability.

\subsection{System implementation: basic requirements and risks}

In order to provide functioning of the first version of the mentioned indicator system, the collection and aggregation of information in the necessary dimension should be provided. In many cases acquired data are of satisfying quality in both spatial and temporal terms, but access to them should be improved in order to avoid specific data acquisition procedures. Information currently acquired and processed by the state statistics institution is limited in terms of spatial resolution, which does not allow a comprehensive evaluation of coastal sustainable development, as it covers a wide range of essential parameters: number of population, employment, social exclusion, economic parameters, etc. Probably some of this information might be acquired directly from municipalities and improvement of data quality and accessibility might be provided by adopting special governmental regulations, also linked to the 
eventual development of a national integrated coastal management plan as is required by main stakeholder groups in Latvia.

Taking into account the existence in Latvia of only the initial the stage of ICZM practice development, there is an obvious need for establishing a SCD national focal point - a structure to aggregate these data and to carry out indicator calculations, perform their analysis and write reports and elaborate other documents and information for the needs of authorities and the general public. These activities should be focused on the needs of users of this information as target customers, e.g., the Ministry of Regional Development and Local Governments; the Ministry of Environment; Boards of Planning regions; Municipality groups, the Association of coastal municipalities (joint development projects), local municipalities and municipality planners (development programmes and spatial planning); as well as a working group developing the integrated coastal management plan etc. Great weight shall be given to the direct exchange of data with municipalities, which could be quite complicated at the moment. However, with the improvement of planning quality and the integrated competence of planners, the municipality level information might become quite important in the future and even replace the limited capacity of the state statistic institution. Regular communication and formalized consultations with data holding institutions, and particularly with target customers, are compulsory.

Several risks affecting the introduction of the indicators system should also be mentioned. There are insufficient activities of state institutions, including legislative bodies, and underassessment of the impact of the coastal issues on the development of the national economy and coastal development planning in particular. The limited spatial resolution of statistical data (since there is an existing plan to have only five statistic regions covering the whole national territory) will result in a lesser possibility of identifying processes occurring in the coastal zone and comparing them with those taking place in inland territories and general country tendencies.

\section{Summary and conclusions}

ICZM has been actively developed at the EU level and is setting corresponding requirements for national/regional planning for all coastal member countries, including the Eastern Baltic, who as recent newcomers are only starting to plan this approach application. The SCD indicator system elaborated under the framework of the Deduce project in general was evaluated in Latvia positively as an eventual introduction of this system would provide new stimulus and new information and knowledge both to local government and national institutions, who are now facing expanding responsibilities towards coastal management. At the same time, requirements are to be recognized for the further improvement of the measurement adequacy of general coastal issues in complementary combination with the parallel introduction of selective measurement adjustments for different diverse EU coastal regions. Active elaboration of national/regional and local coastal indicators case study research projects prepares further practical 
background and theoretical frames for both SCD indicator system development and renewal of ICZM strategies, particularly final and full scale introduction of integrated coastal communication using not only, as usually traditionally perceived, diverse coastal information, but also integrating it with multi-targeted coastal education/training, proactive public participation and partnership building between coastal stakeholders as well as sustainability friendly behaviour enhancement in coastal communities.

The current application of this EU proposed SCD system in Latvia represents, for the moment, an approximately measured general picture of comparatively well balanced coastal development, though this probably does not fully reveal all specific details and risks of this situation, which should be additionally and adequately assessed and taken into account. On the basis of this, the newly elaborated SCD indicators measurement system proposal for Latvia could be directly implemented and will serve for the moment satisfactorily (further improvements for the measurement of several coastal features are already planned), both for national interests (especially in relation to the more integrated assessments and judgements prepared) as well as for EU level management comparisons requested. The coastal sustainability perspective with the ICZM eventual developments in this region, in particular addressing communication instruments at their growing variety of different types and complexities, are to be further studied and at the same time stepwise systemic integrations of coastal sustainability shall be ongoing.

\section{References}

[1] Kudrenickis I., Bisters V., Builevics A., Ernšteins R., Strēle-Birzniece G. Manual Thinking Tools for Municipal Development Planning, Journal of Environmental Research, Engineering and Management (Lithuania, ISSN 1392-1649), No 1 (27), 2004, p.95-101

[2] Kudreņickis I., Ernšteins R., Kauliņš J., Kadikis R. Environmental Information And Systems For Sustainable Coastal Development In Latvia, Proceedings: International conference, Geographic Information Facilities Supporting Access To Environmental Information, Turku, Finland, 2006, pp.18-27

[3] Deduce - EU Interreg III C Program project at: http://www.deduce.eu

[4] Indicators Guideline: To Adopt An Indicator-based Approach To Evaluate Coastal Sustainable Development, Final report by DEDUCE consortium, EU Interreg IIIC Program project, Barcelona, 2007

[5] Benders J., Ernsteins R. Environmental Information, Management in Coastal Municipalities: Liepaja City Case; in "Coastal Resources Management and Communication", Integrated Coastal Management Research School, Salacgriva, Latvia, 2007

[6] Ernšteins R. Local Agenda 21 Process Facilitation: Environmental Communication and Self-Experience Development in Latvia, Book: Filho L.W., Ubelis. A., Berzina D (eds.), Sustainable Development in the Baltic and Beyond, Frankfurt, Peter Lang Europaischer Verlag der Wissenschaften, 2006, pp.305-318 